\title{
A Dynamic Investment Model under Time-Inconsistency*
}

\author{
Bernes Karaçay** \\ Vanderbilt University
}

\author{
Murat Yımaz *** \\ Boğaziçi University
}

\begin{abstract}
In this paper we analyze a three-period dynamic investment model where a principal interacts with an agent who is time-inconsistent. We use $\beta \delta$-preferences to capture time-inconsistency. In every period, the agent invests an amount and then the principal, observing the investment amount, makes an offer or not; finally the agent accepts the offer or not. For both the sophisticated agent (who is aware of his inconsistency) and the naive agent (who is not aware of his inconsistency), we find the optimal investment streams. The difference in their information set is causing them to finalize the game at different periods or to attain different levels of investments. We found that the naive agent ends up investing a higher (or equal) overall amount than the sophisticated agent, and thus the principal is (weakly) better off with a naive agent.
\end{abstract}

Keywords: dynamic investment, time-inconsistency, $\beta \delta$-preferences, sophisticated agent, naive agent. JEL Classification: D03, D82, D86

\section{Zamansal Tutarsızlık altında bir Dinamik Yatırım Modeli}

\section{Özet}

Bu makalede zamansal tutarsızlık içeren tercihlere sahip bir vekil ile temasta olan bir asilin bulunduğu üç periyotluk bir dinamik yatırım modelini inceliyoruz. Zamansal tutarsızlığ $\beta \delta$-tercihleri ile temsil ediyoruz. Her periyot, vekil bir miktar yatırım yapıyor, bunu gözlemleyen asil, vekile bir teklifte bulunuyor ya da bulunmuyor, ardından da vekil, eğer teklif varsa, kabul ediyor ya da etmiyor. Hem sofistike vekil (zamansal tutarsızlığının farkında olan) için hem de naif vekil (zamansal tutarsızlığının farkında olmayan) için optimal yatırım miktarlarını buluyoruz. Farklı vekiller, kendi tutarsızlıkları hakkında sahip oldukları bilgilerin farklı olmasından dolayı farklı periyotlarda oyunu bitirmeyi ve farklı miktarlarda yatırım yapmayı seçiyorlar. Naif vekilin sofistike vekile göre daha yüksek (ya da aynı) miktarda toplam yatırım yaptığını, dolayısıyla asilin, naif vekille karşılaşmayı tercih edeceğini gösteriyoruz.

Anahtar Kelimeler: dinamik yatırım, zamansal tutarsızlık, sofistike ajan, naif ajan, $\beta \delta$-tercihleri. JEL Siniflamasi: D03, D82, D86

\footnotetext{
* This article is derived from Bernes Karaçay's Master's thesis (Karaçay, 2012) entitled “A Dynamic Investment Model under Time-inconsistency."

** Bernes Karacay is a Research Assistant in the Department of Economics at Vanderbilt University, VU Station B, Box \#351819, 2301 Vanderbilt Place, 37235, Nashville, TN, U.S.A. E-mail: bernes.karacay@vanderbilt.edu

*** Murat Yilmaz is an Assistant Profesor in the Department of Economics at Boğazici University, Natuk Birkan Building, 34342, Bebek, Istanbul, Turkey. E-mail: muraty@boun.edu.tr
} 
E xperiments and daily observations provide supporting evidence that people show present biased preferences, or more specifically time-inconsistent behavior, when making decisions over a period of time. In other words, people's preferences change over time;or, something that is desirable at a point of time will not be that desirable at a different point in time. Thus people have a tendency to delay costly actions, for instance, by starting to write a thesis and then going to the gym. However, they want to receive instant gratification, which leads to time-inconsistent behavior. ${ }^{[1]}$

In this paper, we focus on the investment decisions of an agent who is interacting with a principal over time. As a motivating example, we think of various education levels one can pursue, and at a certain level one starts working, potentially with higher wages and benefits when the investment in education is higher ${ }^{[2]}$ We see people getting different levels of education, namely, some people only get a bachelor's degree, some get a master of arts degree, and some pursue a doctoral degree. In the light of this example, we ask the following questions: Why do people end up with different investment levels, and what are the differences in people's preferences which cause this variance in investment levels? Of course, in the education example, there are many reasons and explanations (for instance, job market signaling is one of them) ${ }^{[3]}$ What we want to do is to see if there is a link between the time-inconsistency of an agent and the different investment levels he pursues. More specifically, can we explain different investment levels through different time-inconsistent types of preferences? Can we match the time-consistent agent and the time-inconsistent agent with different investment levels?

In the model we consider, there is an agent and a principal interacting over three periods. During each period, the agent picks an investment level $\theta_{t} \in\left[\theta_{t-1}, \infty\right)$ at cost $\mathrm{c}\left(\theta_{t}-\theta_{t-1}\right)$ The principal observes $\theta_{t}$ and then offers the agent a partnership or not. If there is an offer, then the agent accepts or rejects it. If the agent accepts, the production takes place and the total revenue, $\mathrm{R}\left(\theta_{t}\right)$, is realized. Then, they share the total revenue generated, where the agent gets $\operatorname{sR}\left(\theta_{t}\right)$, the principal gets the rest, and the game ends. Otherwise, they move on to the next period (unless it is the last period). If the agent rejects or the principal does not make an offer, then they move on to the third period (unless it is the last period). If there is no accepted offer at the end of the third period, the game ends and they get no revenue and the agent incurs the cost of all investment he made. We assume that the principal is aware of the type of agent he is dealing with and provides results within this framework, but we also discuss what happens when the principal does not have that piece of information.

We assume that the agent has time-inconsistent preferences. Time-inconsistent preferences are often captured by hyperbolic discount factors, that is, a discounting scheme

\footnotetext{
[1] See Frederick, Loewenstein, O'Donoghue (2002), for an extensive overview of the literature, and see Loewenstein and Prelec (1992) for an extensive survey on anomalies in intertemporal choice.

[2] In Harris and Holmstorm (1982), they show that in the equilibrium wages never decrease with age and increase only when the worker's market value increases above his current wage.

[3] See Spence (1973).
} 
that reflects the change in the preferences over time. More specifically, the agent's time-inconsistency is modeled by $\beta \delta$ preferences. ${ }^{[4]}$ An agent with $\beta \delta$ preferences has a discount factor $\beta \delta$ between the current and the next period, and $\delta$ between any other pair of successive periods. In other words, the agent's preference for a payoff in date $t$ over a payoff in date $t+1$ is stronger as date $t$ gets closer. A time-inconsistent agent may or may not be aware of his inconsistency: A sophisticated agent is fully aware of his inconsistency in the sense that he correctly predicts how his future selves will behave. A naive agent, on the other hand, is not aware of his inconsistency, in the sense that he mis-predicts the behavior of his future selves through an overestimated $\beta$.

The main results of our paper are as follows. ${ }^{[5]}$ Through backward induction, we find the optimal investment streams for both sophisticated and naive types of timeinconsistent agents, as well as the period that each type ends the game. The period the game ends is of importance since the later the game ends, the more delay there is, but also with a potentially a higher level of investment. This resembles the tradeoff between taking a job right after an undergraduate degree and getting a doctoral degree and then getting a job. We also compare these investment levels for both types of agents. If the game ends in the first period, then both the sophisticated and the naive types attain the same investment level.

If the game ends at a later period, $\mathrm{t}=2$ or $\mathrm{t}=3$, the naive type always attains a higher overall investment level than the sophisticated type. In terms of when the game ends, for a sophisticated type of agent, we find that for high values of $\beta$, as $\delta$ increases, the game ends at a higher period, including all $\mathrm{t}=1,2,3$. On the other hand, for relatively low values of $\beta$, the game ends in the first period for low $\delta$ values and ends in the third period for high $\delta$ values, but never ends in the second period. When the agent is naive, however, for a range of $\delta$ values, below a certain $\beta$ value, the agent (after realizing that he is time-inconsistent) changes his mind about his investment decision and finalizes the game in the second period, even though he made an investment in the first period with which he intended to end the game in the third period. Finally, we find that for the principal, it is better that the agent is naive rather than sophisticated for all $\delta$ and $\beta$ values.

This paper is related to a number of other papers in the literature. Phelps and Pollak (1968) first developed the $\beta \delta$ preferences which were later used by Laibson (1997), O'Donoghue and Rabin (1999a,1999b,2001) among many others ${ }^{[6]}$ For instance, O'Donoghue and Rabin (1999a) examine the self-control problem by using $\beta \delta$ preferences. Dellavigna and Malmendier (2004) investigate rational profit maximizing firms and consumers that have time-inconsistent preferences and they characterize the optimal

[4] $\beta \delta$-preferences were first developed by Phelps and Pollak (1968) and later used by Laibson (1997), O'Donoghue and Rabin (1999a,1999b,2001) among others.

[5] We use Matlab to get these results, mainly because the model does not provide us with closed form solutions. The codes are available upon request.

[6] See also Gilpatric (2008), Akın (2009, 2012), Sarafidis (2006), Strotz (1956), Yan (2009a, 2009b) and Y1lmaz(2013, 2015). 
contract that the firm offers for different types of time-consistent and time-inconsistent agents. Chade, Prokopovych and Smith (2008) study infinitely repeated games where players have $\beta \delta$-preferences. O'Donoghue and Rabin (1999b) consider the principalagent relationship with time-inconsistent agents. Eliaz and Spiegler (2006) characterize the optimal menu of contracts when a monopoly is contracting with time-inconsistent agents and show that it includes exploitative contracts for naive agents. In terms of investment decisions, especially regarding investment in education, one of the most influential papers is Spence (1973) which considers the job market signaling where there is an asymmetric information between the employer and the employees. The employer cannot observe the productivity of the worker. However, by getting an education, the employee signals his talent and this will mitigate the inefficiency resulting from the asymmetric information.

The organization of the paper is as follows: In section 2, we briefly describe the model and introduce the types of agent. In section 3, we solve the model for the timeconsistent and the time-inconsistent (sophisticated and naive) agent where we find the optimal streams for each type of agent for each $\delta, \beta$ combination. These results are depicted in the figures and we provide interpretations for them. In the same section, we also compare the overall investment levels of the naive and and the sophisticated agents and answer the question with whom the principal is better off. In section 4, we briefly discuss the incomplete information case, where the principal does not have the information on the type of the agent. Section 5 concludes and provides further discussion. The technical details are given in the Appendix.

\section{The Model}

There are two players, agent and principal, who interact over three periods. ${ }^{[7]}$ The agent decides how much to invest and the principal observes this investment level and decides whether to offer a partnership or not. The agent is time-inconsistent captured through -preferences (which are explained below), whereas the principal is time-consistent with the usual exponential discounting. Now, we give the details of the model.

\section{Timing of The Game}

At time $\mathrm{t}=1$, the agent picks an investment level $\theta_{1} \in[0, \infty)$ which has a $\operatorname{cost} \mathrm{c}\left(\theta_{1}\right)$. Then, the principal observes this investment level and decides whether to offer a partnership or not. If there is an offer, then the agent accepts or rejects it. If the agent accepts, the production takes place and they get a total revenue of $R\left(\theta_{1}\right)$. The agent gets $\operatorname{si}\left(\theta_{1}\right)$ the principal gets the remaining $(1-s) R\left(\theta_{1}\right)$, and the game ends. If there is no offer or the offer is not accepted, they move on to the next period.

${ }^{[7]}$ For the time-inconsistency to be effective, we need at least three periods. 
At any other time $t>1$ where there is no accepted offer in the previous period, the agent chooses an investment level $\theta_{t} \in\left[\theta_{t-1}, \infty\right)$ at a cost $c\left(\theta_{t}-\theta_{t-1}\right)$. The principal observes this investment level and decides whether to offer a partnership or not. Then, the agent decides whether to accept the offer or reject it. If the agent accepts, the production takes place and they get a total revenue of $R\left(\theta_{t}\right)$. The agent gets $s R\left(\theta_{t}\right)$, the principal gets the remaining $(1-s) R\left(\theta_{t}\right)$, and the game ends. Otherwise, they move on to the next period, unless $t=3$. If, at the end of period $t=3$, there is no partnership realized, no production takes place and no revenue is generated.

\section{Agent}

The agent is time-inconsistent. A time-inconsistent agent discounts tomorrow to today by $\delta \beta$, but he discounts any future period to the previous period by only $\delta$, from the viewpoint of today. Thus, his discount factor between two adjacent periods changes over time when he moves to the future periods. This implies that the agent's preferences are changing over time, which is captured by quasi-hyperbolic discounting factors reflecting present-biased preferences.

A time-inconsistent agent can be either sophisticated (SO) or naive (NA). A sophisticated time-inconsistent agent uses quasi-hyperbolic discounting factors $\left(1, \delta \beta, \delta^{2} \beta\right)$ and knows (correctly) that at any future period he will be using this discounting scheme. Note that the discount factor between today and tomorrow is $\delta \beta$, however the discount factor between tomorrow and the day after tomorrow is just $\delta$ from today's point of view. A naive time-inconsistent agent, with discounting $\left(1, \delta \beta, \delta^{2} \beta\right)$, thinks (erroneously) that he will use $\left(1, \delta, \delta^{2}\right)$ at any future period. ${ }^{[8]}$ A naive time-inconsistent agent does not know that he is time-inconsistent at the start of the game, in the first period. When he arrives at the second period however, he learns about his inconsistency and discounts accordingly. We will analyze both types of agent separately.

As a benchmark we will consider a time-consistent agent who has the exponential discount factors $\left(1, \delta, \delta^{2}\right)$. Alternatively one can consider a time-consistent agent who has the exponential discount factors $\left(1, \delta \beta,(\delta \beta)^{2}\right)$. Note that for a time-consistent agent the discount factor between any period $t-1$ and $t$ is constant. Hence the preferences do not change over time.

If the game ends at period $T$ with an offer accepted, then the agent receives $s R\left(\theta_{T}\right)$ at the end of the game at period $T$, and incurs $c\left(\theta_{T}-\theta_{T-1}\right)$ at each period, $t \leq T$ where $1 \leq T \leq 3$ and $\theta_{0}=0$. If the game ends at $t=3$ with no offer or with an offer rejected, then no profit is realized, and the agent only incurs the cost of investment stream. The strategy set of the agent is given by

$$
S_{A}=\left\{s_{A}^{1}:[0, \infty) \times\{A, R\}\right\} \times\left\{s_{A}^{2}:[0, \infty) \rightarrow[0, \infty) \times\{A, R\}\right\} \times\left\{s_{A}^{3}:[0, \infty)^{2} \rightarrow[0, \infty) \times\{A, R\}\right\},
$$

where A stands for Accept and R stands for Reject.

${ }^{[8]}$ A naive time-inconsistent agent might be either fully naive or partially naive. The former case is when the agent thinks his $\beta$ is equal to 1 , and the latter case is when he thinks his $\beta$ is not equal to 1 but still larger than the true value. We consider the former case in this paper. 


\section{Principal}

The principal is time-consistent and has the usual exponential discount factors $\left(1, \delta, \delta^{2}\right)$. If the game ends at period $\mathrm{T}$ with an offer accepted, then the principal receives $(1-s) R\left(\theta_{T}\right)$ at the end of the game at period $T$, where $1 \leq T \leq 3$ and incurs no cost. If the game ends at $\mathrm{t}=3$ with no offer or with an offer rejected, then no revenue is realized and the principal receives zero, his reservation payoff. The strategy set of the principal is given by

$$
S_{p}=\left\{s_{p}^{1}:[0, \infty) \rightarrow[P, N)\right\} \times\left\{s_{p}^{2}:[0, \infty)^{2} \rightarrow[P, N)\right\} \times\left\{s_{p}^{3}:[0, \infty)^{3} \rightarrow[P, N)\right\},
$$

where P stands for Partnership, and N stands for No Partnership.

\section{Complete Information}

In this section, we assume that all of the above is common knowledge and that the principal knows the agent's cost function and whether he is time-consistent or sophisticated time-inconsistent or naive time-inconsistent. We also assume specific revenue and cost functions: and $R(\theta)=\theta$ and $c(\theta)=\theta^{2}$.

\section{Benchmark: Time-consistent Agent}

We assume that the agent is time-consistent with the discounting factor $\delta$. We find the optimal investment streams that would end the game in periods $t=1,2,3$, respectively. First, we start with the optimal payoff stream that would end the game at $t=3$ . Given $\theta_{2}$, in the third period the principal will make an offer for any $\theta_{3} \geq 0$ and the agent maximizes $s \theta_{3}-\left(\theta_{3}-\theta_{2}\right)^{2}$ with respect to $\theta_{3}$. The agent's optimal investment level is $\theta_{3}^{* * *}=\theta_{2}^{* * *}+\frac{s}{2}$.

Lemma 1 For a time-consistent agent, to end the game in the third period, the optimal level of investment at the second period is $\theta_{2}^{* * *}=\theta_{1}^{* * *}+\frac{s \delta}{2}$.

Proof. See the Appendix 6.1 .

Then, the optimal $\theta_{1}^{* * *}$ can be found by maximizing the overall payoff stream at period 1 with respect to $\theta_{1}$. So, the maximization problem is given by:

$\max _{\theta_{1}} \delta^{2}\left[s \theta_{3}-\left(\theta_{3}-\theta_{2}\right)^{2}\right]-\delta\left(\theta_{2}-\theta_{1}\right)^{2}-\theta_{1}^{2}$

where $\theta_{3}=\theta_{2}+\frac{s}{2}$ and $\theta_{3}=\theta_{2}+\frac{s \delta}{2}$ which gives $\theta_{1}^{* * *}=\frac{s \delta^{2}}{2}$. Thus, we have the following lemma:

Lemma 2 The optimal stream for a time-consistent agent that will end the game in the third period is

$\theta_{1}^{* * *}=\frac{\delta^{2} s}{2} \theta_{2}^{* * *}=\frac{\delta s}{2}(1+\delta) \theta_{3}^{* * *}=\frac{s}{2}\left(1+\delta+\delta^{2}\right)$ 
Now, we find the optimal stream of investments that ends the game at the second period. At $t=2$, the agent maximizes $s \theta_{2}-\left(\theta_{2}-\theta_{1}\right)^{2}$ with respect to $\theta_{2}$ and this maximization gives $\theta_{2}^{* * *}=\theta_{1}+\frac{s}{2}$. The optimal investment level at $\mathrm{t}=2$; to end the game at $\mathrm{t}=2$ is $\mathrm{s} / 2$. However this investment level should also be high enough to get an offer. The principal knows that if she does not give an offer in the second period, then the agent will invest $\mathrm{s} / 2$ in the third period. Hence the investment in second period should be higher than the discounted investment of the third period investment.

This is given by $\delta\left(\theta_{2}+\frac{s}{2}\right)<\theta_{2}$, that is $\theta_{2} \geq \frac{\delta s}{2(1-\delta)}$. Hence, to get an offer it must be that $\theta_{2}^{* *}=\theta_{1}+\frac{s}{2} \geq \frac{\delta s}{2(1-\delta)}$, otherwise $\theta_{2}^{* *}$ will not be enough to get offer.

This situation will occur when $\theta_{1}$ is very small and hence the additional investment is not enough to get an offer. In these cases, the agent will choose the (threshold) investment level that receives an offer, which is $\frac{\delta s}{2(1-\delta)}$. So,

$$
\theta_{1}^{*}= \begin{cases}\frac{s \delta}{2(1-\delta)} & \text { if } \quad \theta_{1}<\frac{s(2 \delta-1)}{2(1-\delta)} \\ \theta_{1}^{* *}+\frac{s}{2} & \text { if } \quad \theta_{1} \geq \frac{s(2 \delta-1)}{2(1-\delta)}\end{cases}
$$

Given $\theta_{2}^{* *}$, the optimal level of $\theta_{1}^{* *}$ can be find by maximizing

$\Pi_{A}^{2}=\delta\left[s \theta_{2}-\left(\theta_{2}-\theta_{1}\right)^{2}\right]-\theta_{1}^{2}$

Solving this problem we get the following lemma:

Lemma 3 For a time-consistent agent, to end the game in the second period, the optimal level of investment at the first period is

$$
\theta_{1}^{* *}= \begin{cases}\frac{\delta s}{2} & 1 \geq \delta^{2}+\delta \\ \frac{s \delta^{2}}{2(1-\delta)(1+\delta)} & 1<\delta^{2}+\delta\end{cases}
$$

Proof. See the Appendix 6.1.

Thus, the optimal stream that ends the game in the second period is given in the lemma below:

Lemma 4 The optimal stream for a time-consistent agent that will end the game in the second period is

$$
\left(\theta_{1}^{* *}, \theta_{2}^{* *}\right)= \begin{cases}\left\{\frac{\delta s}{2}, \frac{s(1+\delta)}{2}\right\} & 1 \geq \delta^{2}+\delta \\ \left\{\frac{s \delta^{2}}{2(1-\delta)(1+\delta)}, \frac{\delta s}{2(1-\delta)}\right\} & 1<\delta^{2}+\delta\end{cases}
$$

Finally, the optimal investment level that ends the game in the first period is given in the following lemma: 
Lemma 5 The optimal stream for a time-consistent agent that will end the game in the first period is

$$
\theta_{1}^{*}=\left\{\begin{array}{cl}
\frac{s}{2} & \frac{1}{2}>\delta \\
\frac{s \delta^{2}}{2(1-\delta)} & \text { otherwise }
\end{array}\right.
$$

Proof. See the Appendix 6.1.

Now, given these investment schedules, for any given $\delta$, we find at which period the game ends together with the optimal investment levels, by the help of Matlab.

Proposition 1:Suppose the agent is time-consistent with a discount factor of $\delta$. Then, for any given $\delta$ and s, the equilibrium investment levels are given by

$$
\theta=\left\{\begin{array}{llr}
\left(\theta_{1}^{*}\right) & \text { if } & \delta \leq \underline{\delta} \\
\left(\theta_{1}^{* *}, \theta_{2}^{* *}\right) & \text { if } & \underline{\delta}<\delta \leq \bar{\delta} \\
\left(\theta_{1}^{* * *}, \theta_{2}^{* * *}, \theta_{3}^{* * *}\right) & \text { if } & \bar{\delta}<\delta
\end{array}\right.
$$

where $\theta^{*}, \theta^{* *}, \theta^{* * *}$ are the optimal investment streams that end the game in periods $1,2,3$ respectively.

Proof. See the Appendix 6.1.

For low levels of $\delta$ it is optimal to pick an investment level that receives an offer in the very first period and the agent accepts it. For intermediate levels of $\delta$, it is optimal to pick a stream of investment levels that ends the game in the second period. Note that, for this investment stream, if the investment level in the first period receives an offer, it is optimal for the agent to reject it. Finally for high levels of $\delta$ it is optimal to pick an investment stream in order to end the game in the last period. The intuition for this result is straightforward: As $\delta$ increases, the future periods are getting more valuable, and hence it is optimal to spread the overall investment over two or more periods which is less costly, particularly because the cost function is quadratic.

\section{Sophisticated Agent}

We assume that the agent is time-inconsistent with the discounting scheme $\left(1, \delta \beta, \delta^{2} \beta\right)$. We also assume that the agent is aware of his discounting, that is, he is sophisticated. We find the optimal investment streams that would end the game in periods $t=1 ; 2$; 3 , respectively. Then for each $(\delta, \beta)$ pair, we will find which stream of investments is actually optimal.

First, we find the optimal decisions at $\mathrm{t}=3$. In this last period, the principal will make an offer for any investment level that is bigger than zero, his reservation utility. Given $\theta_{2}$, the agent maximizes $s \theta_{3}-\left(\theta_{3}-\theta_{2}\right)^{2}$ with respect to $\theta_{3}$, and the optimal level is $\theta_{3}^{* * *}=\theta_{2}^{* * *}+\frac{s}{2}$.

Given this optimal investment level in the last period, we have the following lemma: 
Lemma 6 For a sophisticated time-inconsistent agent, to end the game in the third period, the optimal level of investment at the second period is $\theta_{2}^{* * *}=\theta_{1}^{* * *}+\frac{s \delta \beta}{2}$.

Proof. See the Appendix 6.2.

Now, given these optimal levels in the second and the third periods, we solve for optimal strategy in the first period (aiming to take the game to the last period). This optimal level, $\theta_{1}^{* * *}$, can be found by solving the following maximization problem;

$\max _{\theta_{1}} \delta^{2} \beta\left[s \theta_{3}-\left(\theta_{3}-\theta_{2}\right)^{2}\right]-\delta \beta\left(\theta_{2}-\theta_{1}\right)^{2}-\theta_{1}^{2}$

where $\theta_{3}=\theta_{2}+\frac{s}{2}$ and $\theta_{2}=\theta_{1}+\frac{s \delta \beta}{2}$. The optimal level is then $\theta_{1}^{* * *}=\frac{s \delta^{2} \beta}{2}$. Now plugging this $\theta_{1}^{* * *}$, we will get $\theta_{2}^{* * *}$ and $\theta_{3}^{* * *}$. The optimal stream, conditional on the game ending in the third period, is given in the following lemma:

Lemma 7 The optimal stream for a sophisticated time-inconsistent agent that will end the game in the third period is

$$
\theta_{1}^{* * *}=\frac{\delta^{2} s \beta}{2} \theta_{2}^{* * *}=\frac{\delta s \beta}{2}(1+\delta) \theta_{3}^{* * *}=\frac{s}{2}\left(1+\delta \beta+\delta^{2} \beta\right)
$$

Now we find that the optimal stream conditional on the game ends in the second period. In the second period, the agent maximizes $s \theta_{2}-\left(\theta_{2}-\theta_{1}\right)^{2}-\theta_{1}{ }^{2}$ with respect to $\theta_{2}$ and this maximization gives $\theta_{2}^{* *}=\theta_{1}+\frac{s}{2}$. The optimal investment level at $\mathrm{t}=2$ to make the game end at $\mathrm{t}=2$ is simply $\mathrm{s} / 2$, but this additional investment will not be enough to get an offer. To get an offer, it must be $\theta_{2} \geq \frac{\delta s}{2(1-\delta)}$. Hence, $\theta_{2}$ must satisfy the condition $\theta_{2}^{* *}=\theta_{1}+\frac{s}{2} \geq \frac{\delta s}{2(1-\delta)}$; otherwise with $\theta_{2}^{* *}$, the agent will not get an offer, which is the case when $\theta_{1}$ is very small. In these cases, the agent will choose the (threshold) investment level that receives an offer, which is $\frac{\delta s}{2(1-\delta)}$. Thus, we get

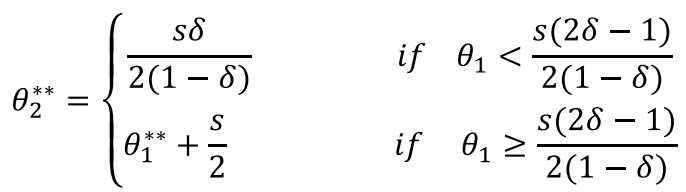

Given $\theta_{2}^{* *}$, the optimal level of level $\theta_{1}^{* *}$ can be found by maximizing the following: $\Pi_{A}^{2}=\delta \beta\left[s \theta_{2}-\left(\theta_{2}-\theta_{1}\right)^{2}\right]-\theta_{1}^{2}$.

We solve this maximization problem and get the optimal stream to end the game in the second period.

Lemma 8 For a sophisticated time-inconsistent agent, to end the game in the second period, the optimal level of investment at the first period is

$$
\theta_{1}^{* *}= \begin{cases}\frac{\delta \beta s}{2} & 1 \geq 2 \delta+\delta^{2} \beta-\delta \beta \\ \frac{s \delta^{2} \beta}{2(1-\delta)(1+\delta \beta)} & 1<2 \delta+\delta^{2} \beta-\delta \beta\end{cases}
$$


The optimal stream for a sophisticated time-inconsistent agent that will end the game in the second period is

$$
\left(\theta_{1}^{* *}, \theta_{2}^{* *}\right)= \begin{cases}\left\{\frac{\delta \beta s}{2}, \frac{s(1+\delta \beta)}{2}\right\} & 1 \geq 2 \delta+\delta^{2} \beta-\delta \beta \\ \left\{\frac{s \delta^{2} \beta}{2(1-\delta)(1+\delta \beta)}, \frac{\delta s}{2(1-\delta)}\right\} & 1<2 \delta+\delta^{2} \beta-\delta \beta\end{cases}
$$

Proof. See the Appendix 6.2.

Lastly, the optimal investment level conditional on the game ending in the first period is given in the lemma below:

Lemma 9 The optimal stream for a sophisticated time-inconsistent agent that will end the game in the first period is

$$
\theta_{1}^{*}=\left\{\begin{array}{lr}
\frac{s}{2} & \frac{1}{2}>\delta \text { and } 1>2 \delta^{2}+\delta^{3} \beta \\
\frac{s \delta}{2(1-\delta)} & \text { otherwise }
\end{array}\right.
$$

Proof. See the Appendix 6.2.

Given the optimal investment streams conditional on ending the game at periods $\mathrm{t}=1 ; 2 ; 3$, we will now determine which of the three streams is actually optimal for any given $(\delta, \beta)$ pair. However, unlike the case where the agent is time-consistent, here we cannot just compare the three overall payoff levels of these three options simply because the discounting is changing over time. Thus, we will first determine, for any $(\delta, \beta)$ pair, the optimal investment levels given the game has reached $\mathrm{t}=2$, and thus we will determine in which period to end the game. When doing this, we use $\delta \beta$ to discount period 3 to period 2 . This is because, the sophisticated agent knows, at period 1 , that, at period 2, he will discount period 3 to period 2 by $\delta \beta$. Then, having determined what is optimal in the second period, we compare the overall payoff levels that arise when the game ends at $\mathrm{t}=1$ with the maximized continuation payoff. When comparing these two, we use the discounting $\left(1, \delta \beta, \delta^{2} \beta\right)$ because now everything is from the viewpoint of the first period.

In the Figure 1, we provide the analysis for $\mathrm{s}=0.7$. Although the investment levels and overall profit levels depend on $\mathrm{s}$, the profit ranking of ending the game in different periods does not depend on s. For any given $(\delta, \beta)$ pair, the figure depicts the period at which the game optimally ends.

We have four observations in Figure 1 regarding both $\delta$, and $\beta$ which reflects the degree of time-inconsistency. (1) For any given $\beta$ which is bigger than 0.45 , as $\delta$ increases, the optimal period to end the game increases. (2) For $0.57<\delta<0.65$, as $\beta$ increases, the agent aims to end the game in the second period rather than the first period. (3) For $0.69>\delta \geq 0.65$, as $\beta$ increases, the agent aims to end the game in the second period rather than the third period. (4) For low values of $\beta$ the game never ends in the second period. The intuitions behind these observations are as follows. 


\section{Figure 1}

The periods at which the game ends for different $(\delta-\beta)$ pairs for a sophisticated agent is $s=0.7$.

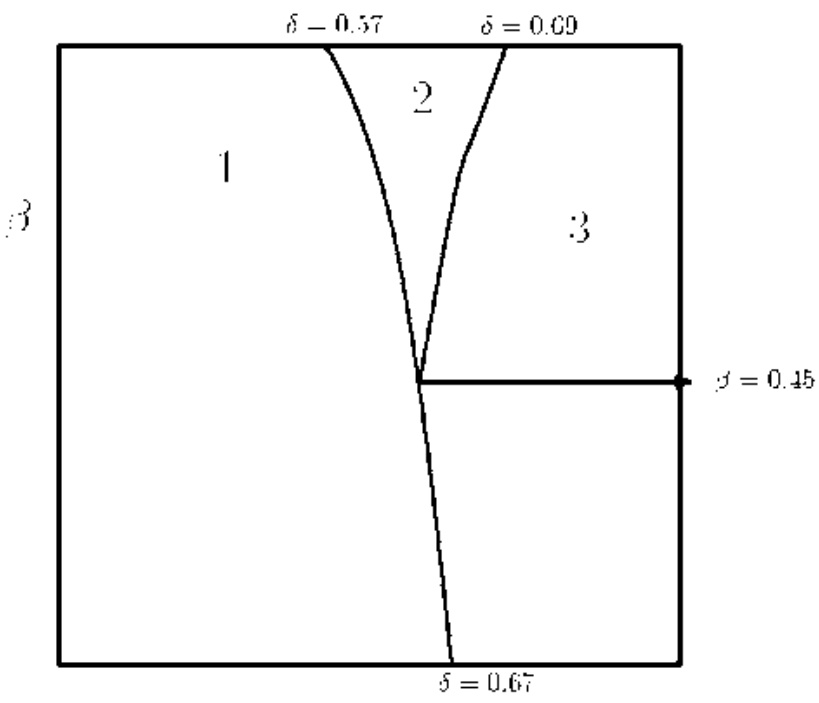

(1) Fixing $\beta$ where $\beta>0.45$, an increase in $\delta$ means that the discounting increases; hence, the latter periods are relatively more valuable. And, the agent is more willing to spread out a total investment over $t=1,2,3$. Because cost function is quadratic, making investment all at once is more costly than spreading it over time. Moreover, for higher, $\delta$ the revenue attained at a future period is also more valuable from the viewpoint of today. Hence by the impact of these two effects, due to an increase in $\delta$, it becomes optimal to spread the overall investment over three periods. Also note that for $\beta=1$, this figure gives us the picture for the time-consistent agent.

(2) For $0.57<\delta<0.65$, as $\beta$ increases, it is optimal to choose an investment stream that ends the game in the second period instead of ending the game in the first period. For example, for $\delta=0.6$, the agent will attain the same investment level for terminating the game at $\mathrm{t}=1$ and $\mathrm{t}=2$, that is, $\theta_{1}=\theta_{2}$. The intuition is that although the investment levels are the same, ending the game at $\mathrm{t}=2$ is less costly because spreading the investment over more periods decreases the cost due to the quadratic cost function. Although the revenue is bigger when terminating the game at $\mathrm{t}=1\left(s^{2} \theta_{1}>\delta \beta\left(s^{2} \theta_{2}\right)\right)$, the difference is getting smaller as $\beta$ increases, and when $\beta=1$ the difference vanishes. However, the cost is smaller for terminating the game at $\mathrm{t}=2$, because the agent divides the same investment level into two parts and spreads it over two periods. ${ }^{[9]}$

(3) For $0.69>\delta \geq 0.65$, when $\beta$ is high, the game ends at $\mathrm{t}=2$; when $\beta$ has a medium value the game finalizes at $\mathrm{t}=3$; and for very small values, the game ends at $\mathrm{t}=1$. The figures 2 and 3 are drawn for $\delta=0.66$. As can be seen, for $\beta<0.6$, the game ends at

${ }^{[9]}$ See the Appendix 6.2. 
$\mathrm{t}=3$, for $\beta>0.6$ the game ends at $\mathrm{t}=2$; and for $\beta<0.2$ the game ends at first period. The reason why the terminal period moves from the third period to the second period is related to the cost structure in the second period. The cost increases with a decreasing $\beta$ for $\beta>0.6$, and the revenue is linear for this region because the investment level is equal to $\frac{s \delta^{2} \beta}{2(1-\delta)(1+\delta \beta)}$; hence the revenue of ending the game in the second period dominates the revenue of ending the game in the third period. Moreover, the agent's profit in the third period, by the viewpoint of the second period, is

$$
\delta \beta\left[s \theta_{3}-\left(\theta_{3}-\theta_{2}\right)^{2}\right]-\left(\theta_{2}-\theta_{1}\right)^{2}
$$

As $\beta$ increases, the revenue ( $\left.\delta \beta s \theta_{3}\right)$ increases quadratically (through $\left.\theta_{3}\right)$. However, the $\operatorname{cost}\left(\delta \beta\left[\left(\theta_{3}-\theta_{2}\right)^{2}+\left(\theta_{2}-\theta_{1}\right)^{2}\right]\right)$ also increases quadratically. Hence, the cost and the revenue functions work in opposite ways. As $\beta$ increases, the agent will become more eager to finish the game in the third period since the revenue increases, but the cost also increases and the agent finds it optimal to finish the game in the second period. Note that in the observation (2) above, the two effects work in the same direction. Hence, as $\beta$ increases, the agent becomes more eager to finish the game in the second period rather than in the first period.

The second period's profit is also bigger than the first period's profit for this region. For instance, for $\delta=0.66$, the investment levels are $\frac{s \delta}{2(1-\delta)}=\theta_{1}^{*}=\theta_{2}^{* *}>\theta_{3}^{* * *}$. The overall investment levels for the first period and for the second period are the same, but the cost of ending the game in the second period is well below that of the first period. This is due to the fact that spreading the same investment level over two periods rather than one period is less costly. The revenue is also smaller in the second period than in that of the first period due to the fact that the agent discounts the same revenue level to the previous period by $\beta \delta$. Hence for low values of $\beta$, it is optimal to finalize the game in the first period, but for high values of $\beta$ finalizing the game in the second period is optimal.

(4) For low values of $\beta$, when $\delta$ is high, the game ends at $\mathrm{t}=3$, and when $\delta$ is low the game finalizes at $\mathrm{t}=1$. The game never ends in the second period. This is because for low values of and $\delta, \beta$ the agent discounts the future too much and it is optimal to finalize the game in the first period. For $\delta<0.5$, he chooses $\theta_{1}^{*}=\frac{s}{2}$ : that is why the profit function is linear in this region. However, for $\delta>0.5$, he chooses $\theta_{1}^{*}=\frac{s \delta}{2(1-\delta)}$ and the profit function strictly decreases in this region. Hence, after some $\delta$, the profit levels of ending the game in the second and third period dominate that of ending the game in the first period, because as $\delta$ increases the future becomes more valuable. However, the second period profit is dominated by the first period profit in region 1 and dominated by the third period profit in region 3 .

The following result is directly observed in Figure 1:

Proposition 2: Suppose the agent is time-inconsistent and sophisticated with a discount scheme $\left(1, \delta \beta, \delta^{2} \beta\right)$ and $\mathrm{s}=0.7$. Then, there are threshold values, $\delta_{1}, \delta_{2}, \delta_{3}$, $\delta_{4}$, such that for any $(\delta, \beta)$ with 
(i) $\delta<\delta_{1}$, it is optimal to end the game in the first period,

(ii) $\delta_{1}<\delta<\delta_{2}$, for low $\beta$ values the game ends in the first period, and for high $\beta$ values the game ends in the second period,

(iii) $\delta_{2}<\delta<\delta_{3}$, for low $\beta$ values the game ends in the first period, and for medium values the game ends in the third period, and for high $\beta$ values it is optimal to end the game in second period.

(iv) $\delta_{3}<\delta<\delta_{4}$, for low $\beta$ values the game ends in the third period, and for high $\beta$ values the game ends in the second period,

(v) $\delta_{4}<\delta$, it is optimal to end the game in the third period.

\section{Naive Agent}

In this section we assume that the agent is time-inconsistent with a discounting scheme $\left(1, \delta \beta, \delta^{2} \beta\right)$, and moreover, he is not aware of this discounting scheme. More specifically, in the first period the naive agent thinks that he is time-consistent and thus uses $\left(1, \delta, \delta^{2}\right)$, and thinks that he will be using this scheme in the future. So, in the first period, he thinks he will discount period 3 to period 2 by $\delta$; however, when he arrives at period 2 , he learns he is time-inconsistent and his discounting scheme is actually $\left(1, \delta \beta, \delta^{2} \beta, \ldots\right)$; thus he discounts period 3 to period 2 by $\delta \beta$. Hence, from the point view of the first period, he solves the problem as a time-consistent agent with a discount factor, $\delta$. As a result, the solution is the same as the time-consistent agent's optimal streams:

$$
\begin{aligned}
& \theta_{1}^{* * *}=\frac{\delta^{2} s}{2} \theta_{2}^{* * *}=\frac{\delta s}{2}(1+\delta) \theta_{3}^{* * *}=\frac{s}{2}\left(1+\delta+\delta^{2}\right) \\
& \left(\theta_{1}^{* *}, \theta_{2}^{* *}\right)=\left\{\begin{array}{lr}
\left\{\frac{\delta s}{2}, \frac{s(1+\delta)}{2}\right\} & 1 \geq 2 \delta+\delta^{2} \beta-\delta \beta \\
\left\{\frac{s \delta^{2}}{2(1-\delta)(1+\delta)}, \frac{\delta s}{2(1-\delta)}\right\} & 1<\delta+\delta^{2}
\end{array}\right. \\
& \theta_{1}^{*}=\left\{\begin{array}{cl}
\frac{s}{2} & \frac{1}{2}>\delta \\
\frac{s \delta}{2(1-\delta)} & \text { otherwise }
\end{array}\right.
\end{aligned}
$$

which end the game in the third, the second and the first periods, respectively.

Thus, depending on his $\delta$, he makes one of the initial investments levels, $\theta_{1}^{*}$ or $\theta_{1}^{* *}$ or $\theta_{1}^{* * *}$. However, in the case where he chooses one of the $\theta_{1}^{* *}$ or $\theta_{1}^{* * *}$, the game moves on to the second period and he learns his type. At that moment, he might realize that the investment levels he was planning to choose may not be optimal anymore. So, he recalculates his optimal investment level(s) from that point on. The agent, for a given $\delta$ (that made him pick an investment level aiming to end the game in the second or third period), has two options in the second period: either aim to end the game in the period 
he initially intended or change his mind and end the game in the other period (in the second period if he intended for the third period, or the third period if he intended to end it in the second period). We look at these two possible cases separately: (1) Suppose he invests $\theta_{1}^{* *}$ and plans to end the game in the second period. Now, he calculates the optimal stream that will take him to the third period ${ }^{[10]}$ Here, we need to consider two different regions. One region is where $1<\delta^{2}+\delta$. For this region, we have

$$
\begin{gathered}
\theta_{1}^{* *}=\frac{s \delta^{2}}{2(1-\delta)(1+\delta)} \theta_{2}^{* * *}=\frac{s \delta^{2}}{2(1-\delta)(1+\delta)}+\frac{\delta \beta s}{2} \\
\theta_{3}^{* * *}=\frac{s \delta^{2}}{2(1-\delta)(1+\delta)}+\frac{\delta \beta s}{2}+\frac{s}{2}
\end{gathered}
$$

The other region is where $1 \geq \delta^{2}+\delta$. For this region, we have

$\theta_{1}^{* * *}=\frac{\delta s}{2} \quad \theta_{2}^{* * *}=\frac{\delta s}{2}+\frac{\delta \beta}{2} \theta_{3}^{* * *}=\frac{\delta s}{2}+\frac{\delta \beta}{2}+\frac{\delta \beta s}{2}$

(2) Now suppose he invests $\theta_{1}^{* *}$ and plans to end the game in the third period. Here he calculates the optimal stream that will terminate the game in the second period. ${ }^{[11]}$

$$
\begin{gathered}
\theta_{1}^{* *}=\frac{s \delta^{2}}{2} \\
\theta_{2}^{* *}= \begin{cases}\frac{s\left(1+\delta^{2}\right)}{2} & 1 \geq \delta^{3}+2 \delta-\delta^{2} \\
\frac{\delta s}{2(1-\delta)} & 1<\delta^{3}+2 \delta-\delta^{2}\end{cases}
\end{gathered}
$$

In the light of these investment levels, Figure 2 below depicts the periods that the game will terminate for any pair of $\delta, \beta$. There is a region where he changes his mind and finishes the game in the second period instead of the third period. Moreover, at that particular region he realizes that he had made a mistake in his investment decision in the first period, that he chose $\theta_{1}^{* * *}$ erroneously instead of $\theta_{1}^{* *}$ which he must have chosen if he had been aware of his time-inconsistency.

\section{Interpretation of Figure 2}

As can be seen in Figure 2, for some $\delta$ and $\beta$ combinations, the agent changes his mind after learning about his inconsistency and decides to end the game in the second period rather than in the third period. For other $\delta$ and $\beta$ combinations, however, there is no change. For example, for $\beta \geq 0.78$ there is no change in the agent's decision (about which period to aim to end the game) even after he learns about his time-inconsistency. For these high values of $\beta$, his time-inconsistency is small, and he has chosen an invest-

\footnotetext{
${ }^{[10]}$ See the Appendix 6.3 .

${ }^{[11]}$ See the Appendix 6.3 .
} 
ment level that is very close to the investment level he picks after he learns his true type. Moreover for $\beta=1$, he makes the same investment as the time-consistent agent. As shown in Figure 2, for $\delta>0.75$, the profit in the third period is larger than the one in the second period.

Figure 2

The periods at which the game ends for different $\delta$ - $\beta$ pairs for the naive agent for $s=0.7$.

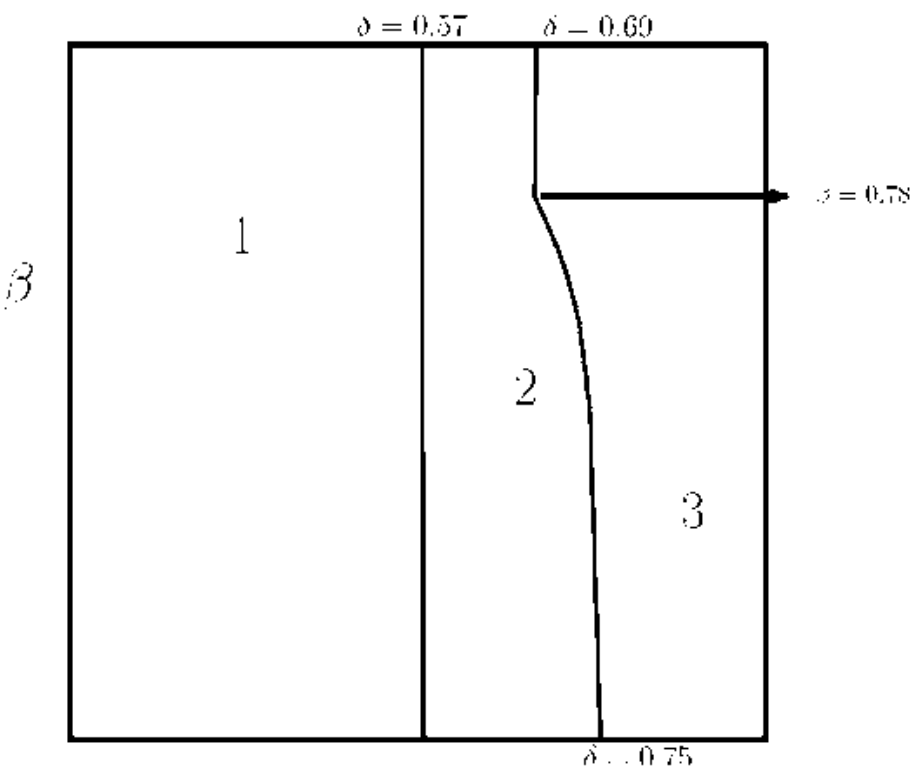

There is a region where the agent, after learning his true $\beta$, changes his mind about his investment decision. For example, for $\delta=0.73$, for low $\beta$ values, he decides to end the game in the second period instead of aiming to end the game in the third period. For such $(\delta, \beta)$ pairs, his intended period to finalize the game, namely the third period, is not optimal anymore once he observes his true $\beta$. He will realize that he is discounting the future more than he thinks. Because the future periods aren't favorable anymore, he ends the game in the second period. Moreover, as $\beta$ decreases, the range of $\delta$ values expands where he changes his mind. This is simply because for $\operatorname{such} \beta \mathrm{s}$, he is discounting the future too much.

Proposition 3:Suppose the agent is time-inconsistent and naive with a discount scheme $\left(1, \delta \beta, \delta^{2} \beta\right)$ and $\mathrm{s}=0.7$. Then, there are threshold values, $\delta_{1}, \delta_{2}, \delta_{3}$ such that for any $(\delta, \beta)$ with

(i) $\delta<\delta_{1}$, it is optimal to end the game in the first period.

(ii) $\delta_{1}<\delta<\delta_{2}$, it is optimal to end the game in the second period. 
(iii) $\delta_{2}<\delta<\delta_{3}$, for high $\beta$ values it is optimal to end the game in the third period, and for low $\beta$ values it is optimal to end the game in the second period where he initially intended to end the game in the third period.

(iv) $\delta_{3}<\delta$, it is optimal to end the game in third period.

\section{Comparison: Overall Investment Levels}

In this section, we look at all optimal investment streams that end the game in periods $\mathrm{t}=1,2,3$ for both naive and sophisticated agents, and then we compare them. We have the following observations directly from the figure below.

Figure 3

Investment levels for both sophisticated and naive agents for $\mathbf{s}=\mathbf{0 . 7}$.

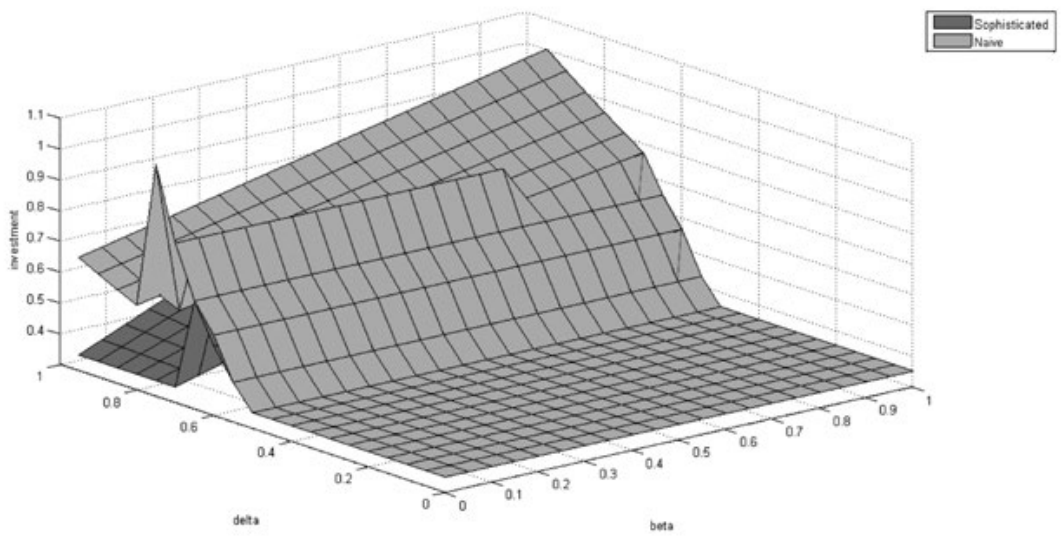

1) For those $\delta \beta$ combinations where they end the game in $\mathrm{t}=1$, both naive and sophisticated agents pick the same investment level, because in the first period they do not use any discount factor. Hence optimization gives the same investment level which is equal to $\frac{s}{2}$, and this investment level gets an offer for $\delta<0.5$. As a result, for this region the investment level is linear. However, is not enough to get an offer for $\delta \geq 0.5$. Hence, for such $(\delta, \beta)$ combinations, the agent chooses an investment level that is the minimum amount to get an offer, which is $\frac{\delta s}{2(1-\delta)}$.

(2) The following lemma compares the investment levels for naive and sophisticated agents:

Lemma 10 For all $(\delta, \beta)$ combinations, the naive agent attains an investment level that is at least as big as the investment level of the sophisticated agent.

Proof. See the Appendix 6.4.

Intuitively, the reason that the naive agent picks a higher investment level is that he is not aware of his time-inconsistency; he thinks he is time-consistent, and he does not know he is going to discount the future more than he thinks. Therefore he is overcon- 
fident about the future and he picks a higher investment today. However, the sophisticated agent is totally aware of his time-inconsistency problem and does not suffer from an over-investment problem in the initial period. Also note that only the first period investments are different. When the naive agent arrives in the second period, he learns about his time-inconsistency and then becomes a sophisticated agent. From then on his investments are the same as the sophisticated one's investments. Since the first period investment is higher for the naive agent (which is shown at the end of Appendix 6.4), the naive's overall investment is also higher.

\section{With whom the Principal is Better off}

The principal's profit is equal $\Pi_{p}=(1-s) \boldsymbol{\theta}$, and it increases in the investment level that the agent attains. Hence, the principal is better off with the agent who attains a higher overall investment level. The principal will weakly prefer the naive agent over the sophisticated agent for all $(\delta, \beta)$. If the agent is naive, the firm can exploit the consumer's naiveté and can get more out of him because the naïve agent is not aware of his time-inconsistency, namely his true $\beta$. Hence, he erroneously makes a high initial investment $\left(\theta_{1}^{* *}, \theta_{1}^{* * *}\right)$, as compared to the sophisticated agent's initial investment level. And the difference in investment levels increases as $(1-\beta)$ increases, that is, as his naivete increases. This is summed up in the following proposition.

Proposition 4: For all $(\delta, \beta)$ combinations, the naive agent attains an overall investment level at least as big as that of the sophisticated agent, and the principal is weakly better off with a naive agent. For a range of $(\delta, \beta)$ combinations, the principal is strictly better off with the naive agent.

\section{Discussion}

\section{Incomplete Information}

There are several ways to extend our model to the incomplete information environment. First, we can assume that the agent has more than one possible cost function and the principal does not know which cost structure the agent will actually use. For instance, we can assume the cost is either $c(\theta)=\left(\frac{\theta}{2}\right)^{2}$ or $c(\theta)=\theta^{2}$. In this case the first period investment levels are going to serve as signals and the principal will update his beliefs about the agent's type (high cost or low cost). We need to use the Perfect Bayesian Nash equilibrium as the solution concept and find all pooling and separating equilibria. However, for a pooling equilibrium, not only will both types need to pick the same investment level in the first period, they should also pick the same in the second and the third periods. In a separating equilibrium, it must be the case that the two types will pick different levels of investments and their types will be revealed, hence from then on the principal will know who he is facing. This analysis turned out to be highly complicated and we leave it for further research.

An alternative way of incorporating incomplete information is to assume that the principal knows that the agent is time-inconsistent but he does not know whether the 
agent is sophisticated or naive. However, when nature tells the agent that he is naïve with some probability, this will involve some information content, which contradicts the definition of naiveté. By providing the agent with this information, namely his type space, we change his information content, hence we change his type space.

Even if we can find a way to expose incomplete information into our setting, it does not help the principal to learn the agent's type (that is, whether he is naive or sophisticated) since the principal's offer thresholds are the same for both the naive and the sophisticated agent. Moreover, if the agent wants to finish in the first period, the principal will fail to get new information because both the naive and the sophisticated agents will definitely choose the same investment level, and the principal will make an offer; this will end the game. Furthermore, there will be a problem if the agent aims to finalize the game in the third period. Revealing his type gives no advantage to the principal; even if the principal makes an offer, the agent will reject the offer and will end up in the third period.

\section{Endogenous Sharing Rule:}

We can think of a sharing rule that depends on the investment level, we can think of a sharing rule that depends on the investment level, $s(\theta)$. Plausible restrictions on such a sharing rule are the following: $s(0)=0, s(\infty)=1, s^{\prime}>0, s^{\prime \prime}<0$. For instance,

$$
\begin{gathered}
s_{1}(\theta)=\frac{\theta}{\theta+1} \\
s_{2}(\theta)= \begin{cases}\frac{\theta}{2} & \theta \in[0,1) \\
1-\frac{1}{2 \theta} & \theta \in[1, \infty)\end{cases}
\end{gathered}
$$

are two possible sharing rules that satisfy those conditions we just mentioned above. We tried the first one; however, the solution turns out to be a lot more complicated and hence it is not easy to get the optimal investment streams.

\section{More General Functional Forms:}

Although the revenue and cost functions we used are specific, they are plausible ones and we believe that using more general functions will not considerably affect our results.

\section{Conclusion}

In this paper, we looked at a three-period dynamic investment model where there is a time-inconsistent agent and a time-consistent principal. The time-inconsistency is captured by $\beta \delta$ preferences. We considered both cases where the agent is aware of his time-inconsistency and where the agent is not aware of his inconsistency but learns his true $\beta$ in the beginning of the second period. However, the sophisticated agent knows his true $\beta$ in the beginning of the first period. For a sophisticated type of agent, for $\beta \mathrm{s}$ above a threshold, we found that for intermediate values of $\delta$ as the degree of timeinconsistency increases, the game ends in the second period rather than the third period. 
When the agent is naive, however, for a range of $\delta$ values, below a certain $\beta$ value, the agent (after realizing that he is time-inconsistent) changes his mind about his investment decision and ends the game in the second period, even though he made an investment in the first period with which he intended to end the game in the third period. We also found that for all $\delta$ and $\beta$ values the naive agent (erroneously) makes an overall investment that is at least as big as that of the sophisticated agent. Also, for the principal, it is better that the agent is naive rather than sophisticated for all $\delta$ and $\beta$ values.

For the second one, although the revenue and cost functions being used are specific, they are plausible ones and we believe that using more general functions will not affect our results considerably.

\section{References}

Akin, Z. (2009). "Imperfect Information Processing in Sequential Bargaining Games with Present Biased Preferences," Journal of Economic Psychology, (30): 642-650.

------, (2012). “Intertemporal Decision Making with Present Biased Preferences," Journal of Economic Psychology, (33):30-47.

Chade, H., Prokopovych, P., and Smith, L. (2008). "Repeated Games with Present-Biased Preferences," Journal of Economic Theory, (139): 157-175.

Eliaz, K. and Spiegler, R., (2006). "Contracting with Diversely Naive Agents," The Review of Economic Studies, (73): 689-714.

Frederick, S., Loewenstein, G., and O'Donoghue, T. (2002). “Time Discounting and Time Preference: A Critical View," Journal of Economic Literature, (40): 351-401.

Gilpatric, S. (2008). "Present-Biased Preferences, Self-Awareness and Shirking," Journal of Economic Behavior and Organization, (67/3-4): 735-754.

Harris, M. and Holmstrom B. (1982). "A Theory of Wage Dynamics," The Review of Economic Studies, (49/3): 315-333.

Laibson, D. (1997). "Golden Eggs and Hyperbolic Discounting," The Quarterly Journal of Economics, (112/2): 443-477.

Loewenstein, G. and Prelec, D. (2007). "Anomalies in Intertemporal Choice: Evidence and an Interpretation," Journal of Economic Theory, (132): 493-506.

Luttmer, Erzo G.J. and Mariotti, T. (2007). "Efficiency and Equilibrium when Preferences are Timeinconsistent," The Quarterly Journal of Economics, (112/2): 443-477.

O’Donoghue, T. and Rabin, M. (2001) “Choice and Procrastination," The Quarterly Journal of Economics, (116/1): 121-160.

-----, (1999a). “Doing It Now or Later,” American Economic Review, (89/1): 103-124.

-----, (1999b). “Incentives for Procrastinators,” The Quarterly Journal of Economics, Vol. 114, No.3, pp. $769-816$.

Phelps, E. S. and Pollak, R.A. (1968). "On Second-Best National Saving and Game-Equilibrium Growth," The Review of Economic Studies, (35/2): 185-199.

Sarafidis, Y. (2006). "Games with Time-Inconsistent Players,” SSRN WP. 
Spence, M. (1973). “Job Market Signaling,” The Quarterly Journal of Economics, (87/3): 355-374.

Strotz, R.H. (1956). "Myopia and Inconsistency in Dynamic Utility Maximization," The Review of Economic Studies, (23/3): 165-180.

Yan J. (2009a). “Contracting with Heterogeneous Quasi-Hyperbolic Agents: Investment Good Pricing under Asymmetric Information,” Working paper.

-----, (2009b). "Moral Hazard Model with Short-run Impatience and Imperfect Self-awareness," Working paper.

Yilmaz, M. (2013) "Repeated Moral Hazard with a Time-Inconsistent Agent," Journal of Economic Behavior and Organization, (95): 70-89.

(2015). "Contracting with a Naive Time-Inconsistent Agent: To Exploit or not to Exploit?," Mathematical Social Sciences, (77): 46-51. 


\section{Appendix}

\section{Time-consistent Agent}

Proof of Lemma 1 To get the optimal level of investment in the second period in order to end the game in the third period, he maximizes $\delta\left[s \theta_{3}-\left(\theta_{3}-\theta_{2}\right)^{2}\right]-\left(\theta_{2}-\theta_{1}\right)^{2}$ where $\theta_{3}=\theta_{2}+\frac{s}{2}$. Then, $\max _{\theta_{2}} \delta\left[s \theta_{2}-\frac{s^{2}}{2}-\frac{s^{2}}{4}\right]-\left(\theta_{2}-\theta_{1}\right)^{2}$ gives optimal $\theta_{2}^{* * *}$ which is the optimal investment level that ends the game at the third period

$$
\theta_{2}^{* * *}=\theta_{1}^{* * *}+\frac{s \delta}{2}
$$

Proof of Lemma 3. To get the optimal stream of investment that will end game at the second period, define $\frac{s(2 \delta-1)}{2(1-\delta)}=K$.

Then, if $\theta_{1}<\frac{s(2 \delta-1)}{2(1-\delta)}=K$, we have $\theta_{2}=\frac{\delta s}{2(1-\delta)}$. Then, solving

$$
\max _{\theta_{1}} \delta\left[s \theta_{2}-\left(\theta_{2}-\theta_{1}\right)^{2}\right]-\left(\theta_{1}\right)^{2}
$$

we get $\delta\left(\theta_{2}-\theta_{1}\right)=\theta_{1}$, which implies

$$
\frac{\delta \theta_{2}^{*}}{1+\delta}=\theta_{1}^{*}
$$

Thus we get

$$
\theta_{1}^{*}=\frac{s \delta^{2}}{2(1-\delta)(1+\delta)} .
$$

We also need to check whether this $\theta_{1}^{*}$ is smaller than $\mathrm{K}$ or not, that is $\frac{s \delta^{2}}{2(1-\delta)(1+\delta)}<\frac{s(2 \delta-1)}{2(1-\delta)}$ which implies $1<\delta^{2}+\delta$.

For second case $\theta_{1} \geq \mathrm{K}$ and $\theta_{2}=\theta_{1}+\frac{s}{2}$. Then solving

$$
\max _{\theta_{1}} \delta\left[s\left(\theta_{1}+\frac{s}{2}\right)-\left(\theta_{2}-\theta_{1}\right)^{2}\right]-\left(\theta_{1}\right)^{2}
$$

we get $\delta s=2 \theta_{1}$ which implies

$$
\theta_{1}^{*}=\delta s / 2
$$

thus, the optimal stream of investment is

$$
\left(\theta_{1}^{* *}, \theta_{2}^{* *}\right)=\left\{\begin{array}{ll}
\left\{\frac{s \delta^{2}}{2(1-\delta)(1+\delta)}, \frac{s \delta}{2(1-\delta)}\right\} & 1<\delta^{2}+\delta \\
\left\{\frac{s \delta}{2}, \frac{s(1+\delta)}{2}\right\} & 1 \geq \delta^{2}+\delta
\end{array} .\right.
$$

Proof of Lemma 5.Now we find the optimal investment level to end the game in the first period.

First of all we must guarantee that the investment level $\theta_{1}$ gets an offer in the first period, which means that it must give higher payoff to the principal in the first period than the payoff the principal gets in the second and third periods. The payoffs of the principal from the first period point of view are as follows. In the first period, she gets $(1-s) \theta_{1}$ in the second period she gets $\delta(1-s) \theta_{2}$, and in the third period she gets 
$\delta^{2}(1-s) \theta_{3}$ supposing that $\theta_{1}<K$. We will check the payoff for the principal and see whether the first period is optimal or not to offer a partnership. This means that $\Pi_{1}^{p}>\Pi_{2}^{p}$ and, $\Pi_{1}^{p}>\Pi_{3}^{p}$ that both hold. For the first inequality we need $\frac{s \delta^{2}}{2(1-\delta)}$ which is obtained using $\theta_{1}>\theta_{2}^{* *}=\frac{s \delta}{2(1-\delta)}$ and $(1-s) \theta_{1} \quad>\delta(1-s) \theta_{2}$. For the second inequality we need $\theta_{1}<\frac{\delta^{2} s(1+\delta)}{2\left(1-\delta^{2}\right)}$ which is obtained from the fact that in this region $\theta_{3}^{* * *}=\theta_{1}+\frac{s}{2}+\frac{s \delta}{2}$ and $\delta^{2}(1-s) \theta_{3}<(1-s) \theta_{1}$.

However the first condition contradicts $\theta_{1}<K$ since $\frac{(2 \delta-1) s}{2(1-\delta)}>\theta_{1}>\frac{s \delta^{2}}{2(1-\delta)}$ implying that $0>(\delta-1)^{2}$, which is a contradiction. Hence ending at the first period is not profitable for the principal for the first case.

Now suppose, $\theta_{1} \geq \mathrm{K}$. We will again check $\Pi_{1}^{p}>\Pi_{2}^{p}$ and $\Pi_{1}^{p}>\Pi_{3}^{p}$. The first condition implies $\theta_{1}>\frac{\delta s}{2(1-\delta)}$ since $\theta_{2}^{* *}=\theta_{1}+\frac{s}{2}$ and $(1-s) \theta_{1}>\delta(1-s) \theta_{2}$. The second condition implies $\theta_{1}>\frac{\delta s}{2(1-\delta)}$ since $\delta^{2}(1-s)\left(\theta_{3}\right)<(1-s) \theta_{1}$ and $\theta_{3}^{* * *}=\theta_{1}+\frac{s}{2}+\frac{s \delta}{2}$

However, we have $\frac{\delta s}{2(1-\delta)}>\frac{\delta^{2} s}{2(1-\delta)}$, hence $\frac{\delta s}{2(1-\delta)}$ is the minimum amount that guarantees getting an offer for the partnership when we compare the second and third period payoffs with that of the first period for the principal. Hence, the optimal amount of investment to finish the game in the first period is as follows:

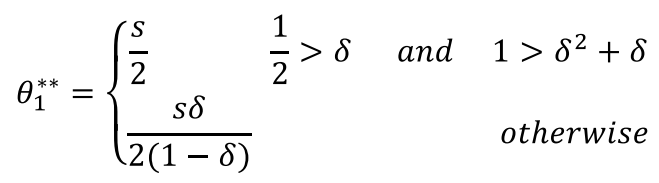

Proof of Proposition 1: Ending the game in periods $t=1 ; 2 ; 3$ gives the following profit levels for the agent, respectively.

$$
\begin{aligned}
& \Pi_{A}^{1}= \begin{cases}\frac{s^{2}}{4} & \frac{1}{2}>\delta \\
\frac{s^{2} \delta}{2(1-\delta)}-\left(\frac{s^{2} \delta}{2(1-\delta)}\right)^{2} & \text { otherwise }\end{cases} \\
& \Pi_{A}^{2}= \begin{cases}\delta\left[\frac{\delta s^{2}}{2(1-\delta)}-\left(\frac{s \delta}{2(1-\delta)(1+\delta)}\right)^{2}\right]-\left(\frac{s \delta^{2}}{2(1-\delta)(1+\delta)}\right)^{2} & 1<\delta^{2}+\delta \\
\delta\left[\frac{s^{2}(1+\delta)}{2}-\frac{s^{2}}{2}\right]-\frac{s^{2} \delta^{2}}{4} & 1 \geq \delta^{2}+\delta\end{cases} \\
& \Pi_{A}^{3}=\delta^{2}\left[\frac{s^{2}}{2}\left(\delta^{2}+\delta+1\right)\right]-\frac{s^{2}}{4}-\delta\left[\frac{s \delta}{2}\right]^{2}-\frac{\delta^{4} s^{2}}{4}
\end{aligned}
$$


We find thresholds $(\underline{\delta}, \bar{\delta})$ by Matlab. ${ }^{[12]}$ The algorithm works like this: First it compares $\Pi_{A}^{3}$ and $\Pi_{A}^{2}$ by the point of view of the second period by treating the first period's investment level as a sunk cost. Hence we find two regions: $\delta$ where the game ends in the second period and where the game ends in the third period. Then, we calculate $\Pi_{A}^{1}$ and first we compare it to the payoff if the game ends in the third period profit, from the point of view of the first period, and we get a third region. However, for this region the optimal stream of investment levels that send the game to the third period gives a higher profit, hence $\bar{\delta}$ is determined by comparison with the second and third periods. Second, we compare the second and first periods and we find regions where $\Pi_{A}^{1} \geq \Pi_{A}^{1}$, hence we find $\underline{\delta}$. By this comparison we find thresholds $(\underline{\delta}, \bar{\delta})$ and these thresholds are $\delta=0.57$ and $\delta=0.69$. For $\delta$ 's smaller than 0.57 , the time-consistent agent chooses $\theta_{1}^{*}$ and ends the game in the first period. For $0.57<\delta<0.83$ the game ends in the second period, and the agent chooses an optimal stream $\left(\theta_{1}^{* *}, \theta_{2}^{* *}\right)$ that ends game in the second period. For $\delta>0.83$ the game ends in the second period, and the agent chooses an optimal stream of investment levels, $\left(\theta_{1}^{* * *}, \theta_{2}^{* * *}, \theta_{3}^{* * *}\right)$, that ends the game in the third period.

\section{Sophisticated Agent}

Proof of Lemma 6. To get the optimal investment level in the second period for the sophisticated agent to take the game to last period, the agent maximizes $\delta \beta\left[s \theta_{3}-\left(\theta_{3}-\theta_{2}\right)^{2}\right]-\left(\theta_{2}-\theta_{1}\right)^{2}$ where $\theta_{3}=\theta_{2}+\frac{s}{2}$ and $\max _{\theta_{2}} \delta \beta\left[s \theta_{2}-s^{2} / 2-s^{2} / 4\right]\left(\theta_{2}-\theta_{1}\right)^{2}$. This gives the optimal $\theta_{2}^{* * *}$ which is the optimal investment level in the second period that ends the game in the third period. It is obtained as $\theta_{2}^{* * *}=\theta_{1}^{* * *}+s \delta \beta / 2$.

Proof of Lemma 8. We get the optimal stream of investment levels that will end the game in the second period. We again define $\frac{(2 \delta-1) s}{2(1-\delta)}=K$. Suppose $\theta_{1}<K$. Then $\theta_{2}=\frac{s \delta}{2(1-\delta)}$. Then, solving

$$
\max _{\theta_{1}}=\delta \beta\left[s \theta_{2}-\left(\theta_{2}-\theta_{1}\right)^{2}\right]-\theta_{1}^{2}
$$

we get $\frac{\delta \beta \theta_{2}^{* *}}{1+\delta \beta}=\theta_{1}^{* *}$, which implies

$$
\theta_{1}^{* *}=\frac{s \delta^{2} \beta}{2(1-\delta)(1+\delta \beta)}
$$

${ }^{[12]}$ The Matlab codes are available on request. 
Moreover for $\theta_{1}^{*}$ to be smaller than $\mathrm{K}$ we need

$\frac{s \delta^{2} \beta}{2(1-\delta)(1+\delta \beta)}<\frac{(2 \delta-1) s}{2(1-\delta)} \rightarrow 1<2 \delta-\delta \beta+\delta^{2} \beta$

For the second case $\theta_{1} \geq K$ and $\theta_{2}=\theta_{1}+s / 2$

$\max _{\theta_{1}} \delta \beta\left[s\left(\theta_{1}+\frac{s}{2}\right)-\left(\theta_{2}-\theta_{1}\right)^{2}\right]-\theta_{1}^{2}$

we get $\theta_{1}^{* *}=\delta \beta s / 2$. Hence, the optimal stream of investment to end the game in the second period is

$\left(\theta_{1}^{* *}, \theta_{2}^{* *}\right)=\left\{\begin{array}{cc}\left\{\frac{s \delta^{2} \beta}{2(1-\delta)(1+\delta \beta)}, \frac{s \delta}{2(1-\delta)}\right\} & 1<2 \delta-\delta \beta+\delta^{2} \beta \\ \left\{\frac{s \delta \beta}{2}, \frac{s(1+\delta \beta)}{2}\right\} & 1 \geq 2 \delta-\delta \beta+\delta^{2} \beta\end{array}\right.$.

Proof of Lemma 9. We get the optimal stream of investment levels that will end the game in the first period. We'll check $\Pi_{1}^{p}>\Pi_{2}^{p}$ and $\Pi_{1}^{p}>\Pi_{3}^{p}$
$(1-s) \theta_{1}$
$\delta(1-s) \theta_{2}$
$\delta^{2}(1-s) \theta_{3}$

Suppose $\theta_{1}<K$.

First condition $\Pi_{1}^{p}>\Pi_{2}^{p}$ implies $(1-s) \theta_{1}>\delta(1-s) \theta_{2}$ and in this region we have $\theta_{2}^{* *}=\frac{\delta s}{2(1-\delta)}$, hence $\theta_{1}$ must satisfy the following condition $\theta_{1}>\frac{s \delta^{2}}{2(1-\delta)}$.

The second condition $\Pi_{1}^{p}>\Pi_{3}^{p}$ implies $\delta^{2}(1-s)\left(\theta_{3}\right)<(1-s) \theta_{1}$ and in this region region we have

$\theta_{3}^{* * *}=\theta_{1}+\frac{s}{2}+\frac{s \delta \beta}{2}$. Hence we get $\theta_{1}<\frac{\delta^{2} s(1+\delta \beta)}{2\left(1-\delta^{2}\right)}$.

However the first condition contradicts $\theta_{1}<K$ since $\frac{(2 \delta-1) s}{2(1-\delta)}>\theta_{1}>\frac{s \delta^{2}}{2(1-\delta)}$ which implies $0>(\delta-1)^{2}$ which is a contradiction. Hence ending the game at the first period is not profitable for the principal for the first case.

Thus, suppose $\theta_{1} \geq K$.

We will check $\Pi_{1}^{p}>\Pi_{2}^{p}$ and $\Pi_{1}^{p}>\Pi_{3}^{p}$.

The first condition $\Pi_{1}^{p}>\Pi_{2}^{p}$ implies $(1-s) \theta_{1}>\delta(1-s) \theta_{2}$ and in this region $\theta_{3}^{* *}=\theta_{1}+\mathrm{s} / 2$.

Hence $\theta_{1}$ must satisfy $\theta_{1}>\frac{\delta s}{2(1-\delta)}$.

The second condition $\Pi_{1}^{p}>\Pi_{3}^{p}$ implies $\delta^{2}(1-s) \theta_{3}<(1-s) \theta_{1}$ and in this region we have

$$
\theta_{3}^{* * *}=\theta_{1}+\frac{s}{2}+\frac{s \delta \beta}{2} \text {. Hence } \theta_{1}>\frac{\delta^{2} s(1+\delta \beta)}{2\left(1-\delta^{2}\right)} .
$$


However $\frac{\delta s}{2(1-\delta)}>\frac{\delta^{2} s}{2(1-\delta)}$, hence $\frac{\delta s}{2(1-\delta)}$ is the minimum investment level that guarantees getting the partnership offer when we compare the second and the third period payoffs with the one in first period. Hence the optimal amount of investment in the first period is as follows:

$$
\theta_{1}^{*}=\left\{\begin{array}{lr}
\frac{s}{2} & \frac{1}{2}>\delta \text { and } 1>2 \delta^{2}+\delta^{3} \beta \\
\frac{s \delta}{2(1-\delta)} & \text { otherwise }
\end{array}\right.
$$

Interpreting Figure 1. Analytically ending the game at $\mathrm{t}=2$ gives the following profit in the viewpoint of today:

$$
\left(\theta_{2}^{* *}-\theta_{1}^{* *}\right)=\left\{\begin{array}{cc}
\left\{\beta\left[s \theta_{2}-\left(\theta_{2}-\theta_{1}\right)^{2}\right]-\theta_{1}^{2}\right. \\
\left\{\frac{s \delta^{2} \beta}{2(1-\delta)(1+\delta \beta)}-\frac{s \delta}{2(1-\delta)}\right\} & 1<2 \delta-\delta \beta+\delta^{2} \beta \\
\left\{\frac{s \delta(1+\delta \beta)}{2}\right\} & 1 \geq 2 \delta-\delta \beta+\delta^{2} \beta
\end{array} .\right.
$$

Or simply,

$$
\left(\theta_{2}^{* *}-\theta_{1}^{* *}\right)=\left\{\begin{array}{lr}
\frac{s}{2} & 1 \geq 2 \delta+\delta^{2} \beta-\delta \beta \\
\frac{s \delta}{2(1-\delta)(1+\delta \beta)} & 1<2 \delta+\delta^{2} \beta-\delta \beta
\end{array} .\right.
$$

For medium values of $\delta$, terminating game at $\mathrm{t}=1$ and $\mathrm{t}=2$ give the same investment level $\theta_{1}=\theta_{2}=\frac{s \delta}{2(1-\delta)}$.

As $\beta$ rises, it becomes optimal to distribute the investment between the first and second periods since the cost function is quadratic and the cost decreases $\delta \beta\left(\frac{s \delta}{2(1-\delta)(1+\delta \beta)}\right)^{2}$ as $\beta$ rises. Moreover, the profit $\delta \beta s\left(\frac{s \delta}{2(1-\delta)}\right)$ also increases as $\beta$ rises. Hence, the agent becomes more incline to spread the investment between the first and second periods as $\beta$ increases.

\section{Naive Agent}

Given the initial investment $\theta_{1}^{* *}$, where

$$
\theta_{1}^{* *}= \begin{cases}\frac{\delta s}{2} & 1 \geq \delta+\delta^{2} \\ \frac{s \delta^{2}}{2(1-\delta)(1+\delta)} & 1<\delta+\delta^{2}\end{cases}
$$

the agent calculates the optimal stream that takes the game to the third period. 
The first case $1<\delta+\delta^{2}$ gives $\theta_{1}^{* *}=\frac{s \delta^{2}}{2(1-\delta)(1+\delta)}$ and solving

$$
\max _{\theta_{2}} \delta \beta\left[s \theta_{3}-\left(\theta_{3}-\theta_{2}\right)^{2}\right]-\left(\theta_{2}-\theta_{1}\right)^{2}
$$

where optimal $\theta_{3}=\theta_{2}+\frac{s}{2}$ hence we get

$$
\begin{aligned}
& \frac{\delta \beta s}{2}+\theta_{1}^{* *}=\theta_{2}^{* *} \\
& \frac{s}{2}+\theta_{2}^{* * *}=\theta_{3}^{* * *}
\end{aligned}
$$

that is

$$
\begin{gathered}
\frac{\delta \beta s}{2}+\frac{s \delta^{2}}{2(1-\delta)(1+\delta)}=\theta_{2}^{* * *} \\
\frac{\delta \beta s}{2}+\frac{s \delta^{2}}{2(1-\delta)(1+\delta)}+\frac{s}{2}=\theta_{3}^{* * *}
\end{gathered}
$$

The second case $1<\delta+\delta^{2}$ implies $\theta_{1}^{* *}=\frac{\delta s}{2}$. Similarly, we get

$$
\begin{gathered}
\theta_{2}^{* * *}=\frac{\delta s}{2}+\frac{\delta s}{2} \\
\theta_{3}^{* * *}=\frac{\delta s}{2}+\frac{\delta s}{2}+\frac{\delta \beta s}{2}
\end{gathered}
$$

Given the initial investment $\theta_{1}^{* * *}$, the optimal $\theta_{2}$ that ends at second period is equal to $\theta_{2}^{* *}=\theta_{1}+\frac{s}{2}$. Hence,

$$
\theta_{2}^{* *}=\frac{\delta^{2} s}{2}+\frac{s}{2}=\frac{s}{2}\left(\delta^{2}+1\right)
$$

However, we have to check whether or not this optimal stream gets the offer. To see this, note that $\frac{s}{2}\left(\delta^{2}+1\right) \geq \frac{s \delta}{2(1-\delta)}$ implies $1 \geq \delta^{3}+2 \delta-\delta^{2}$.

Thus

$$
\theta_{2}^{* *}= \begin{cases}\frac{s\left(1+\delta^{2}\right)}{2} & 1 \geq \delta^{3}+2 \delta-\delta^{2} \\ \frac{\delta s}{2(1-\delta)} & 1<\delta^{3}+2 \delta-\delta^{2}\end{cases}
$$

\section{Naive Agent vs Sophisticated Agent}

The optimal $\theta_{1}$ levels for the naive agent are as follows 


$$
\begin{gathered}
\theta_{1}^{* * *}=\frac{\delta s}{2} \\
\theta_{1}^{* *}= \begin{cases}\frac{\delta s}{2} s \delta^{2} & 1 \geq \delta+\delta^{2} \\
\frac{s(1-\delta)(1+\delta)}{2\left(1-\delta+\delta^{2}\right.}\end{cases} \\
\theta_{1}^{*}= \begin{cases}\frac{s}{2} & \frac{1}{2}>\delta \\
\frac{s \delta}{2(1-\delta)} & \text { otherwise }\end{cases}
\end{gathered}
$$

The optimal $\theta_{1}$ streams for the sophisticated agent are as follows:

$$
\begin{gathered}
\theta_{1}^{* * *}=\frac{\delta^{2} s \beta}{2} \\
\theta_{1}^{* *}=\left\{\begin{array}{lc}
\frac{\delta \beta s}{2} & 1 \geq 2 \delta+\delta^{2} \beta-\delta \beta \\
\frac{s \delta^{2} \beta}{2(1-\delta)(1+\delta \beta)} & 1<2 \delta+\delta^{2} \beta-\delta \beta
\end{array}\right. \\
\theta_{1}^{*}= \begin{cases}\frac{s}{2}>\delta \text { and } 1>2 \delta^{2}+\delta^{3} \beta \\
\frac{s \delta}{2(1-\delta)} & \text { otherwise }\end{cases}
\end{gathered}
$$

Since $\beta \leq 1$, the naïve agent's initial $\theta_{1}$ investment levels are bigger than those of the sophisticated agent. 